\title{
SATELlite-BASEd Vegetation HeALTh INDICES AS A CRITERIA FOR INSURING
}

\section{Against Drought-Related Yield LosSes}

Bokusheva R. ${ }^{1 *}$, Kogan F. ${ }^{2}$, Vitkovskaya I. ${ }^{3}$, Conradt, S. ${ }^{1}$, Batyrbayeva M. ${ }^{3}$

${ }^{1}$ Swiss Federal Institute of Technology, ETH Zurich

${ }^{3}$ NOAA, National Environmental Satellite Data and Information Services

${ }^{2}$ Space Research Institute of the National Space Agency of the Republic of

Kazakhstan

*corresponding author; phone: +41 44632 5330; fax: +41 44632 1086;

e-mail: bokushev@ethz.ch 


\section{DROUGHT-RELATEd YIELd LOSSES}

\section{$4 \quad$ Abstract}

5 This paper considers the use of indices built on the basis of remote-sensing data for crop

6 insurance purposes. In our analysis, we compare the capacity of two satellite-based vegetation

7 health (VH) indices, the vegetation condition index (VCI) and the temperature condition index

8 (TCI), measured for important periods of the crop vegetation to predict farmers' wheat yields in

9 two main grain producing regions of Kazakhstan. The selected indices are used for the design of

10 index-based insurance contracts. The dependence of wheat yields on vegetation conditions as

11 measured by VCI and TCI, is modeled by applying the copula approach. Our empirical results

12 for 47 grain-producing farms in the Northern Kazakhstan show that insurance contracts built on

$13 \mathrm{VH}$ indices can provide substantial risk reductions for a group of farms, though on average for

14 the whole sample, risk reductions were found to be moderate. The study results suggest that the

15 effectiveness of insurance contracts can be improved using satellite data of higher resolutions

16 and measuring indices at more disaggregated levels.

17 Keywords: satellite-based vegetation health index, drought-related yield losses, wheat, 18 agricultural insurance, copula approach. 


\section{Introduction}

21 Agricultural production is a risky economic activity. In addition to market, institutional, political

22 and farmers' individual risks, production risk, in the form of adverse weather conditions,

23 presents an important source of risk in agricultural production. Drought, floods, frost, hurricanes

24 etc can partially or completely destroy farmers' harvests and in this way seriously endanger

25 individual farmers' livelihoods. Although farmers generally have many options for reducing their

26 exposure to adverse weather events on farm, such as the use of irrigation, drought resistant crop

27 varieties and the cultivation of crops with shorter production cycles, etc., the risk reducing

28 capacity of farm based risk management strategies might be not sufficient to cope with extreme

29 weather events. In this situation, farmers' risks can be more effectively managed by employing

30 crop insurance.

Extreme weather events usually have a systemic occurrence pattern, i.e. they simultaneously

32 affect a number of agricultural producers. This feature of extreme weather events presents an

33 important prerequisite for the introduction of so called index-based insurance. In contrast to the

34 traditional yield insurance, index-based insurance is based not on the actual farm yields, but on

35 an index. Accordingly, an indemnity is paid whenever the realized value of the index exceeds or

36 falls below a threshold index value (Skees et al., 1997). In the case of weather-based insurance,

37 the indemnification (i.e. the insurance payment to compensate the farmer's yield loss) is

38 conditioned on the actual realization of a selected weather index. An aggregate yield index is

39 used in the case of area-based yield insurance to detect crop failure. As in the case of index-

40 based insurance yield losses are assessed on the basis of an index (not on the farmer's actual

41 yield), this type of crop insurance allows a substantial reduction of insurance administrative and

42 other costs (because in this case there is no need to monitor single farm yields). In the last 
43 decade, several studies have been conducted to evaluate the potential effectiveness of insurance

44 contracts based on weather and area yield-based indices (e.g. Skees et al., 1997; Turvey, 2001;

45 Vedenov and Barnett, 2004; Breustedt et al., 2008; Kellner and Musshoff, 2011; Bokusheva and

46 Breustedt, 2012).

47 The effectiveness of index-based insurance products is, however, highly dependent on the 48 availability of reliable and cost-effective information sources. In the case of weather-based 49 insurance, a rather sparse meteorological network is often considered a handicap for the 50 development of this type of crop insurance. Additionally, in contrast to the data from ground 51 weather stations, satellite images can be used to derive independent and in some cases more 52 reliable information about plant growing conditions.

53 In recent decades, satellite images have been increasingly used for agricultural purposes. The 54 so-called satellite-based vegetation health $(\mathrm{VH})$ indices, which include the vegetation condition 55 index (VCI), the temperature condition index (TCI) and the vegetation health index (VHI) 56 (Kogan, 1998; Unganai and Kogan, 1998; Kogan et al., 2012, Kogan et al., 2015), have been 57 developed and used to predict crop yields in different regions with high variations in climatic and 58 ecosystem conditions since 1982.

59 Recently, Barrett et al. (2008) discussed the potential for the application of remote-sensing 60 data for the purpose of crop insurance. They suggest that high resolution remote-sensing data can 61 seriously reduce problems of a high basis risk, i.e. the risk that occurs because of an imperfect 62 correlation between an index and farmers' yields (Barrett et al., 2008), which might result in a 63 mismatch between farmers' actual yield losses and insurance payments. 
In recent years, several pilot projects have been implemented to evaluate the effectiveness of

65 index-based insurance by employing satellite-based VH indices in such countries as Canada,

66 India, Mali and Kenya (Hazell et al., 2010; Miranda and Farrin, 2012). However, satellite-based

67 VH indices have been used to design insurance primarily for pasture vegetation, which yield is

68 directly related to the quantity of green biomass generated during the vegetation period.

A more recent study by Makaudze and Miranda (2010) developed index-based insurance

70 employing satellite data for maize and cotton. This study focused on Zimbabwe and was based

71 on time series of the Normalized Difference Vegetation Index (NDVI) and maize and cotton

72 yields aggregated at the district level. The authors found that insurance contracts based on the

73 NDVI allowed a higher risk reduction than rainfall-based insurance contracts.

74 Although the results of some studies have shown that VHI, VCI and TCI show considerable

75 correlation with observed crop yields, the quality of satellite data is not always sufficient and can

76 differ from plot to plot, as well as for different periods of measurement (Kogan et al., 2003). In

77 addition, empirical research has shown that the use of aggregated yields might cause serious

78 undervaluation of the farm yield variability and an underestimation of the farm risk (Claasen and

79 Just, 2010). Therefore, in our view, the applicability of satellite images for the design of

80 insurance products should be evaluated by using long time series of satellite data and farm

81 yields. The novelty of the present study compared to previous analyses on the use of remote-

82 sensing data for insurance purposes is that for the first time it conducts the analysis of the

83 satellite data in combination with farm yield data. Moreover, to model the dependence between

84 crop yields and remote sensing indices, our study employs the copula approach, which,

85 compared to linear correlation, presents a more adequate methodological framework for

86 modeling dependence in the tails of multivariate distributions (Embrechts et al., 2002). 
87 In this paper, we analyze the effectiveness of two VH indices for insuring wheat yield losses

88 in grain producing farms in Kazakhstan. Kazakhstan is an important grain producing nation. In

89 the period from 2003 to 2012 the national average wheat production was 13.8 million metric tons

90 (National Agency of Statistics of the Republic of Kazakhstan, 2012). Both the high level of

91 production and a relatively low domestic consumption of 6.2 million metric tons of wheat in

922010 (USDA, 2012) make Kazakhstan a key player in the world grain market and are important

93 factors assuring the country's contribution to global food security. However, the national grain

94 production can vary substantially from year to year subject to weather conditions during the

95 vegetation period. Drought presents the main natural hazard to Kazakhstan's grain producers and

96 is an important source of fluctuation in farm income. For example, in 2010, due to an extensive

97 drought, the national wheat yield dropped to 0.73 tons per ha, while in 2011 - a year with very

98 favorable weather conditions - it rose to 1.66 tons per ha.

99 The remainder of the paper is structured as follows: Section 2 presents the methodology and 100 empirical procedure employed in the study. Section 3 provides a description of the data. The 101 following section presents and discusses study results. Conclusions are drawn in the final 102 section.

103

104 2. Methods

105

\subsection{Satellite-based vegetation health indices}

106 The change in the green biomass of crops within the vegetation period is traditionally described 107 by means of two well known remote sensing indices: the Normalized difference vegetation index 108 (NDVI) and the vegetation conditions index (VCI) (Kogan, 1998; Lui and Kogan, 1996). NDVI 
109 quantifies the total amount of green biomass in each pixel of a satellite image during the 110 measurement period; VCI is obtained by normalizing NDVI values by their multi-year absolute 111 minimum and maximum values in the analyzed period. For any given year and pixel in a satellite 112 image, the VCI in week $w$ is calculated as follows:

$$
V C I_{w}=100 \cdot \frac{N D V I_{w}-N D V I_{\min }}{N D V I_{\max }-N D V I_{\min }}
$$
$N D V I_{\max }$ and $N D V I_{\min }$ are the absolute maximum and minimum values of the NDVI over

115 the entire observation period, respectively. The NDVI is derived from visible (VIS) and nearly 116 infrared (NIR) data as (NDVI=(NIR-VIS)/(NIR+VIS)). The principle of this index is based on 117 the fact that moisture stressed vegetation has a higher reflectance in the VIS and lower in the 118 NIR than green healthy vegetation (Spivak et al., 2008). Higher NDVI values indicate well119 watered, not moisture stressed vegetation. Dry years are characterized by drought related thermal 120 and moisture vegetation stress, resulting in low levels of green biomass and accordingly low 121 NDVI values. Other factors such as salinity, crop diseases and insects can also contribute to a 122 reduction in green reflectance, but these mostly result in local effects, whereas drought has a 123 large scale spatial effect. This allows the use of satellite-based VH indices to detect and measure 124 the effects of drought.

125 Additionally, we employed the TCI, which quantifies land surface thermal condition, 126 including the vegetation canopy (Kogan et al., 2012). For any given year and pixel in a satellite 127 image, the TCI in week $w$ is calculated using the Brightness Temperature (BT) as follows:

128

$$
T C I_{w}=100 \cdot \frac{B T_{\max }-B T_{w}}{B T_{\max }-B T_{\min }},
$$


129 where $B T_{w}, B T_{\max }$ and $B T_{\min }$ are the smoothed brightness temperature, and its multi-year 130 absolute maximum and minimum, respectively (Unganai and Kogan, 1998).

131 Both the TCI and the VCI have been found to exhibit a high level of correlation with yields 132 for different crops (Kogan, 1995; Kogan et al., 2012). The VCI and the TCI are usually 133 calculated for either a week or a 10-day interval. However, when analyzing long times series of 134 data, more stable and reliable results can be obtained by applying integral values of these indices 135 (Spivak et al., 2008). In our analysis, we calculated the integral value of indices for four 136 consecutive weeks.

\subsection{Copula approach}

139 The copula approach has been used extensively for modeling multivariate dependence structures

140 in finance and actuarial mathematics. Recently, several applications of the copula approach have 141 been carried out in the field of agricultural economics (Vedenov, 2008; Zhu et al., 2008;

142 Bokusheva, 2011; Goodwin and Hungerford, 2015).

143 According to Sklar's theorem (Sklar, 1959), if F is a joint distribution function with marginal 144 distributions $F_{1}, \ldots, F_{d}$, then there exists a copula $C:[0,1]^{d} \rightarrow[0,1]$ such that for all $x_{1}, \ldots, x_{d}$ in $145 \bar{R}=[-\infty, \infty]$,

$146 \quad \mathrm{~F}\left(\mathrm{x}_{1}, \ldots, \mathrm{x}_{\mathrm{d}}\right)=\mathrm{C}\left(\mathrm{F}_{1}\left(\mathrm{x}_{1}\right) \ldots, \mathrm{F}_{\mathrm{d}}\left(\mathrm{x}_{\mathrm{d}}\right)\right)$,

147 where $x_{1}, \ldots, x_{d}$ is a vector of $d$ random variables forming a joint distribution, and $F_{1}, \ldots, F_{d}$ are 148 respective marginal distributions. 
Therefore, according to Sklar's theorem, any continuous multivariate distribution can be 150 uniquely described by two parts: the marginal distributions $F_{i}$ and the multivariate dependence 151 structure captured by the copula C. Sklar's theorem makes the copula approach a powerful 152 instrument for modeling empirical joint distributions. In particular, it allows to reduce an 153 empirical problem of modeling a multivariate dependence structure to the selecting appropriate 154 marginal distributions and fitting an adequate copula.

155 In general, there are many different copula families. In empirical research, however, the 156 most commonly applied copulas are the Gaussian copula, Student's $t$ copula and three 157 Archimedean copulas: the Clayton, Gumbel and Frank copulas (Nelsen, 1999; McNeil et al., 158 2005).

159 To design and rate an index-based insurance contract, we employ the approach as presented 160 in Mainik and Schaanning (2012). In particular, we assume that the dependence between crop 161 yields and $\mathrm{VH}$ indices might be stronger in the left tail of the distribution than if measured for 162 entire range of the distribution. Thus, in our analysis we suggest focusing on the expected value 163 of the yield $\tilde{\mu}^{*}$ given that the satellite-based VH index $W$ falls below its critical level, and in 164 particular, its value at risk $\operatorname{VaR}$ at the confidence interval $\alpha, \operatorname{VaR} \alpha(W)$, i.e.:

$165 \quad \tilde{\mu}^{*}=\tilde{\mu}_{\mid W \leq V a R_{1-\alpha}(W)}=E\left(Y \mid W \leq \operatorname{VaR}_{1-\alpha}(W)\right)$,

166 where $E$ is the expectation operator.

167 The expression in (4) can be defined in terms of a copula as follows (Mainik and 168 Schaanning, 2012):

169

$$
\mathrm{H}_{\mathrm{Y} \mid \mathrm{W}=\mathrm{w}}(y)=c_{G(Y) \mid F(W=w)}(v)_{\begin{array}{l}
G(y)=v \\
F(w)=u
\end{array}}
$$


170 where $F(W)$ and $G(Y)$ are marginal distributions of the index and crop yield, respectively.

$171 \mathrm{H}_{\mathrm{Y} \mid \mathrm{W}=\mathrm{w}}(y)$ is the conditional distribution of the yield variable, which can be derived by taking

172 the first derivative of the copula with respect to $u$, i.e.

$173 \quad c_{G(Y) F(W=w)}(v)=\frac{\partial}{\partial u} C(u, v)_{F(w)=u}$,

174 To consider all realizations of the index variable below its $\mathrm{VaR},(5)$ has to be rewritten as:

175

$$
c_{G(Y) F(W) \leq 1-\alpha}(v)=\frac{1}{P(F(W) \leq 1-\alpha)} \int_{l=0}^{1-\alpha} \frac{\partial}{\partial u} C(u, v)_{\substack{F(w)=l \\ G(y)=v}} \partial l
$$

The expression in (7) allows the determination of the conditional distribution of the yield

177 variable in terms of a copula and the marginal distribution of the $\mathrm{VH}$ index. By integrating the

178 expression in $(7)$ over the interval $[0,1]$ of the yield marginal distribution allows to obtain the

179 yield distribution quintile corresponding to $\tilde{\mu}^{*}$. Thus, $\tilde{\mu}^{*}$ can be determined and successively

180 applied for the derivation of insurance contract parameters, i.e. potential indemnity payments

181 and fair insurance premium ${ }^{2}$ (Bokusheva, 2014).

\subsection{Empirical procedure}

184 We start our empirical analysis by identifying for each study county the most critical period of 185 the wheat vegetation, i.e. the period that is most important for the grain formation and wheat 186 yield productivity. This period was determined by detecting the weeks with the highest level of

\footnotetext{
${ }^{2}$ Fair insurance premium does not incorporate any loading related to administrative costs of insurance companies etc. and is calculated as the expected indemnity value.
} 
187 dependency between VH indices and wheat yields using county-level yield data. ${ }^{3}$ To estimate 188 dependence between the county average wheat yields and satellite-based VH indices, we employ 189 four different copula models: the Gaussian, Clayton, Frank, and Gumbel survival copulas. While 190 the Clayton and the Gumbel survival copulas assume a strong dependence in the left tail of the 191 joint multivariate distribution, the Gaussian ${ }^{4}$ and Frank copulas require radial symmetry of joint 192 distribution, i.e. the same level of dependence in opposite corners of the copula.

193 In the second part of the analysis, we use the indices selected in the first step to estimate 194 dependence between them and wheat yields at the farm level. Subsequently, we apply the 195 Cramer-von-Mises criterion to select the most appropriate copulas for modeling dependence 196 between selected indices and farm yields. Hypothetical insurance contracts represented by 197 indemnity payments and the insurance premium were specified on the basis of expressions (4) 198 and (7). In the final step, we evaluate the risk-reducing effectiveness of insurance contracts by 199 comparing the risk of wheat yield revenues with and without insurance using the conditional 200 value at risk - a downside risk measure (McNeil et al., 2005). In our empirical application we 201 define downside risk as probability of the index realization below the third decile $(\mathrm{p}=0.3)$ of 202 index marginal distribution. Consequently, the conditional value at risk is computed as $203 E S=\frac{1}{0.3} \int_{p=0}^{0.3} q_{p} d p$ with $q_{p}$ being the yield distribution $p$-quantile.

\footnotetext{
${ }^{3}$ We measure dependence for vegetation indices computed for weeks between the beginning of June to the mid of September. Traditionally, the period around heading has the highest correlation (0.6-0.8) and drops to the minimum prior to this phase and thereafter.

${ }^{4}$ The Gaussian copula corresponds with the linear correlation concept. Accordingly, the Pearson's correlation coefficient is used to model dependence for this copula.
} 


\section{Data}

206 Satellite data were extracted from NOAA's Global Vegetation Index (GVI) data set 207 (http://www.noaa.gov/satellites.html). The GVI is produced from the top of the atmosphere 208 reflectance in the VIS $(0.58-0.68 \mu \mathrm{m})$, NIR $(0.725-1.1 \mu \mathrm{m})$ and emission in infrared (IR 10-11 $209 \mu \mathrm{m})$ spectral bands, obtained from digital counts recorded by the Advanced Very High 210 Resolution Radiometer (AVHRR) onboard NOAA polar-orbiting satellites in the 'afternoon 211 orbit'. The counts were converted to reflectance by applying pre-launch and post-launch 212 calibration coefficients. The daily observations at $1.1 \mathrm{~km}$ resolution were aggregated to $16 \mathrm{~km}$ 213 and seven day composites to obtain the data in near real time for the entire globe. In our study, 214 VCI and TCI indices were computed for every pixel and week during the period 1982-2010.

215 Furthermore, average values of VCI and TCI were calculated for the grain cultivation areas in 216 each county studied (for more details on this procedure see Spivak et al, 2008).

217 The location of the study counties is shown in Figure 1. Three of the counties - Zelinograd 218 (C1), Atbasar (C2) and Esil (C3) - are situated in the Akmola oblast ${ }^{5}$, and two of them - Denis 219 (C4) and Kamysty (C5) - are located in the Kostanay oblast. As we could not obtain any data for 220 the borders of single farms and small administrative divisions, the VCI and TCI were collected 221 for all AVHRR-based $16 \mathrm{~km}$ pixels inside each county. Mean county's values of these indices 222 were obtained averaging all pixels inside rectangular area covering the principal part of each C1223 C5 counties. Since wheat is growing everywhere in each county and is planted in a short period 224 of time (USDA 1994), such aggregation is warranted. Table 1 provides the area of aggregation 225 and the number of the aggregated pixels. Spatial variation of VH indices for these pixels (24-31)

\footnotetext{
${ }^{5}$ Oblasts are largest administrative units in Kazakhstan. They consist of several counties.
} 
226 did not exceed $12 \%$, which corresponds to variation of precipitation over relatively small areas in

227 Kazakhstan (Kogan et al 2003). statistics for the period 2003-2013, it occupied on average $81.6 \%$ and $80.4 \%$ of the sown areas

231 in Akmola and Kostanay, respectively (National Agency of Statistics of the Republic of 232 Kazakhstan, 2012). Other important crops in these regions are also grains, such as spring barley 233 and oats. Since 1988, the prevalent crop rotation in these two grain producing regions has been 234 fallow-wheat-wheat-barley-wheat (Suleimenov and Akshalov, 2011).

235 Although Kazakhstan is a large country, the spring wheat calendar is quite similar for many 236 main grain-producing regions (variations in the timing of sowing might result in a difference of 237 one or two weeks at maximum) and from year-to-year. Traditionally, wheat is sown in the last 238 10-days of May, heading takes place predominantly at the end of June/ beginning July, followed 239 by the ear emergence phase in July and finally ripening and harvesting in August, or at the

240 beginning of September. In general, phenological dates show limited variation between the main 241 grain producing regions in Northern Kazakhstan.

243 The county and farm yield data for the same time span were obtained from regional statistical 244 offices. The wheat yield time series were tested for structural breaks and adjusted for a time 245 trend using linear, and second- and third-degree polynomial functions. Figure 2 shows the 246 development of average wheat yields in the study counties. It exemplifies that severe droughts in 
1984, 1989, 1991, 1995, 1997, 1998 and 2010 caused dramatic yield declines in all five of the

248 study counties.

249 The marginal distributions of wheat yields and both VH indices were modeled using one of 250 the following distribution families: Normal, Log-normal, Logistic, Log-logistic, Gamma and 251 Weibull distributions. The most appropriate distribution was determined employing the 252 Kolmogorov-Smirnov test.

254 Summary statistics of index and farm yield data can be found in Table A1 of the appendix.

\section{4. Results and discussion}

256 Our empirical results reveal a relatively strong relationship in the joint distributions of wheat 257 yields and each of two VH indices. The magnitudes of the Pearson's correlation coefficients 258 between wheat yields at the county level and the VH indices range between 0.63 and 0.77 for 259 VCI, and 0.64 and 0.79 for TCI (Table 2). The estimates of dependency between VH indices and 260 county wheat yields are very consistent across all three copula models employed in the study 261 with critical periods coinciding across all four copula models for each county ${ }^{7}$. According to our 262 estimates, the periods with the highest dependence differ only marginally across single counties 263 in the case of VCI. They span the period between weeks $26^{\text {th }}$ (end of June) and $31^{\text {st }}$ (end of July)

264 , which correspond to the phenological phases of "ear emergence" and "grain formation", i.e. the

\footnotetext{
${ }^{7}$ Dependence parameters for Clayton, Frank, and survival Gumbel copulas have other measurement scales than the Gaussian copula. In the case of the Clayton copula, the dependence parameter is defined in the interval $[-1, \infty) \backslash\{0\}$, for the Frank copula the feasible interval is $[-\infty, \infty) \backslash\{0\}$, and for the Gumbel copula it takes values $[1, \infty)$ (Nelsen, 1998). Higher values of dependence parameters indicate a stronger dependence.
} 
two most influential phases in formation of spring wheat yield. However, we have found more

266 divergent results for TCI. In three of the study counties, Zelinograd, Atbasar and Esil, TCI seems

267 to be mostly influential in weeks 29 (mid July) - 34 (mid August), while for the other two study

268 counties, which are situated in the Northwest of the country, soil surface temperature seems to be 269 decisive for the wheat formation several weeks earlier, namely in weeks 25-29.

Using the Cramer-von-Mises criterion we found that the survival Gumbel copula provided

272 best statistical fits for most study farms when modeling the dependence between VCI and farm 273 yields, whereas the Frank copula was more adequate in most cases when estimating dependence 274 of farm yields on TCI. These findings suggest that the sensitivity of wheat yields on VCI can be 275 modeled more adequately by a copula allowing for an asymmetric dependence, namely with a 276 stronger dependence in the left tail of the joint distribution; while the relationship between wheat 277 yields and TCI seems to demonstrate a radial symmetry suggesting the same extent of 278 dependence in the left and right tails of the joint distribution. Considering the above-mentioned 279 results, in the following we reduce the scope of our analysis to results obtained using these two 280 copula models.

281 Our estimates of relative risk reduction presented in the upper part of table 3 show that the 282 study farms could benefit only to a limited extent from VCI- and TCI-based insurance contracts 283 when selecting relevant indices/periods based on the county average yields. On average, VCI284 based insurance could reduce the downside risk of farm wheat yields by $25 \%$ when designing 285 insurance contracts on the survival Gumbel copula estimates. The corresponding estimate 286 obtained employing Frank copulas is $22 \%$. TCI-based insurance contracts seem to provide 
slightly higher relative risk reductions, 29 and $26 \%$ on average for survival Gumbel and Frank

288 copulas, respectively (Table 3). However, the performance of both VCI- and TCI-based 289 insurance contracts vary substantially across single counties and farms. According to our 290 estimates the average risk reduction were the highest in Kamysty county in the case of the VCI291 based insurance, while for TCI-based contracts the highest average risk reductions were found 292 for Denis and Kamysty counties.

Considering relatively low risk reduction estimates obtained when detecting relevant vegetation weeks based on the county yields, in the next step we examine whether the riskreducing effectiveness of satellite index-based insurance can be improved when selecting indices

297 on the basis of farm yields. The later procedure caused practically no shift in the relevant periods

298 for most farms from Atbasar county, but for majority of farms from other four counties. For the 299 later, the critical periods moved from one to two weeks later in the case of VCI, spanning overall 300 the period from the 30 th to 35 th weeks. As for TCI, no considerable changes in critical periods 301 were found for most farms from Atbasar, Esil and Kamysty counties; yet the critical period 302 shifted to an earlier period (weeks 27-30) for most farms from Zelinograd county and to a later 303 period (by one week) for farms from Denis county. Results presented in the lower part of Table 3 304 show that the farm-yield-based index selection procedure attained substantially higher risk 305 reductions than the county-yield-based procedure for farms from Zelinograd, Kamysty and Denis 306 counties in the case of VCI-based contracts. A small increase in the average risk reduction due to 307 VCI-based insurance contracts is also observable for farms from Esil county. However, the 308 average risk reduction hardly changed for the study farms from Atbasar county, since, as 309 mentioned above, the period for measuring VCI did not change between county-based and farm 
310 based procedures for most farms in this county. The risk reducing performance of the TCI-based

311 contracts did not show considerable differences between two procedures employed for index

312 selection.

313 For the VCI insurance, the highest risk reductions were found for farms from Zelinograd and

314 Kamysty counties with the average estimates of 0.57 and 0.52 , respectively. A group of farms

315 from Denis county would also benefit from VCI-based insurance. However, most farms in this

316 county would achieve higher risk reductions using TCI-based contracts. The average risk

317 reduction estimates for farms in Atbasar and Esil were found to be very low for both VCI- and

318 TCI-based insurance contracts. We believe that a low risk reduction for these two counties could

319 be explained by quality of yield or satellite data rather the lack of dependence between yield and

$320 \mathrm{VH}$ indices in these two counties in general.

321 Furthermore, our estimates for both types of contracts suggest that a higher effectiveness of 322 insurance contracts is attained using the survival Gumbel copula. This finding might be 323 surprising taking into account that Frank copulas showed a better fit for most farms when 324 modeling the dependence of farm yields on TCI. It can be explained by the fact that the 325 goodness-of-fit test evaluates copula models considering the entire interval of the distribution.

326 Accordingly, it selects a copula model that shows a good fit in both tails of the joint distribution.

327 Given that the survival Gumbel copula shows a strong left tail dependence and a relatively week 328 right tail dependence, it might be tested as showing a worse fit than a copula with radial 329 symmetry in the case of joint distributions with a considerable magnitude of dependence in the 330 right tail. However, the later would not assure that the radial copula provides the best fit in the 331 left tail of the distribution. In the context of our empirical analysis, this implies that the Frank 332 copula might show best fits when evaluating the entire interval of joint distributions of TCI and 
333 farm yields, but the survival Gumbel copula might be better suited to model left tail dependence

334 between TCI and farms yields. Actually, our empirical results support the conclusion that the 335 relationship between TCI and study farm yields in the left tail can be better captured by survival 336 Gumbel copulas.

Our study results show that the performance of both index-based insurance schemes varies substantially not only among study counties (Table 3) but also among single farms within

340 counties (Figure 4). While a number of farms could achieve considerable risk reductions (for a 341 group of 16 farms risk reduction estimates are found to be above 50\%), there is a number of 342 farms (12 farms primarily in Atbasar and Esil counties) for which risk reduction was estimated to 343 be below $25 \%$. For remaining 19 farms, we have found only moderate magnitudes of risk 344 reduction, between 25 and 50\%. The later finding implies that the indices used in our analysis do 345 not sufficiently represent vegetation conditions for some study farms. This might happen because 346 we used relatively low resolution AVHRR data. Additionally, our indices were measured at the 347 county level, not for single farm parcels. This procedure could negatively affect the performance 348 of the VCI- and TCI-based insurance contracts.

349 If comparing VCI- and TCI-based insurance contracts for single farms (Figure 4), one can 350 see that there is an only small group of farms that would attain higher or comparable risk 351 reductions using TCI-based contracts instead of VCI-based contracts. These later farms are 352 situated in Denis county. This finding suggests that there are some local effects that cause TCI 353 slightly outperform VCI in this county. 
Finally, we want draw attention to a high variation in risk reduction estimates within single

355 counties. These differences might be related to both geographical location and soil specifics, and

356 technological aspects of production. During the Soviet time farms used relatively similar

357 technologies, whereas since the mid-1990s there have been considerable differences in

358 technologies applied and intensities of input use among single farms. These later differences may

359 explain considerable deviations in productivity and risk exposure at the farm level.

\section{Conclusions}

This paper analyses the applicability of two satellite-based VH indices-VCI and TCI-to insure

363 yield losses of wheat-producing farms in Kazakhstan. The methodological contribution of the

364 study consists in applying the copula approach for estimating dependence between VH indices

365 and crop yields, and designing and rating insurance contract. The empirical relevance of the

366 study relies on the use of the farm yield time series and the application of satellite data for the

367 development of index-based insurance for grain crops.

368 Different copula models were employed and tested for their adequacy to represent the 369 dependence structure in the tails of joint distributions of two $\mathrm{VH}$ indices and wheat yields. Our 370 empirical results for wheat-producing farms in Kazakhstan showed that survival Gumbel copula 371 provided a better fit when modeling joint distributions of farm wheat yields and VCI, while 372 Frank copulas showed a better performance in describing dependence of farm yield on TCI.

373 Furthermore, our analysis revealed that the performance of the satellite-based VH index

374 insurance varies substantially among farms: while for one third of sample farms yield risk could 375 be reduced by $70 \%$ on average, for a quarter of sample farms risk reduction was estimated to be 
$37616 \%$. These findings suggest that in general $\mathrm{VH}$ indices can provide a solid basis for detecting

377 drought-related yield losses. However, their performance strongly depends on quality of yield

378 and satellite data, as well as regional and local specifics. The effectiveness of the satellite-based

379 VH index insurance can be improved by employing satellite data of a higher resolution, using 380 more sophisticated way of time aggregation of $\mathrm{VH}$ indices, and constructing $\mathrm{VH}$ indices for 381 single farms. Multi-year weekly indices at $4 \mathrm{~km}$ resolution are currently available from NOAA 382 web (http://www.star.nesdis.noaa.gov/smcd/emb/vci/VH/index.php). Another options to increase 383 risk-reducing effectiveness of satellite index-based insurance would be to (a) complement it with 384 information on crop sowing dates for more accurate selection of critical periods in plants' 385 response to weather; (b) use VHI (combined VCI and TCI), which often correlates stronger with 386 crop yield than individual indices (Kogan et all 20115, Kogan et all 2012).

387 Finally, differences in the risk reduction estimates between two index selection procedures 388 based on county yields and farm yield suggest that index-based insurance, designed by using 389 aggregate index and yield data, could involve a relatively high basis risk, that might affect the 390 demand for this kind of insurance. This puts a premium on the development of insurance 391 products based on more precise data, i.e. farm-level yields and higher resolution satellite data.

\section{Acknowledgement}

393 The authors thank financial support of the Swiss National Science Foundation within its Program 394 of Scientific Co-operation between Eastern Europe and Switzerland (SCOPES). 


\section{References}

398

399

400

401

402

403

404

405

406

407

408

409

410

411

412

413

414

415

416

417

418

Barnett, B. J., Barrett, C. B., Skees, J. R. 2008. Poverty traps and index-based risk transfer products. World Development, 36(10), 2045-2102.

Bokusheva, R., Breustedt, G. 2012. The effectiveness of weather-based index insurance and area-yield crop insurance: How reliable are ex post predictions for yield risk reduction? Quarterly Journal of International Agriculture, 51(2), 135-156.

Bokusheva, R. 2014. Improving the effectiveness of weather-based insurance: An application of copula approach. Working paper, MPRA (Munich Personal RePEc Archive).

Bokusheva, R. 2011. Measuring dependence in joint distributions of yield and weather variables. Agricultural Finance Review 71(1), 120-141.

Breustedt, G., Bokusheva, R., Heidelbach, O. 2008. The potential of index insurance schemes to reduce farmers' yield risk in an arid region. Journal of Agricultural Economics, 59(2), 312328.

Claassen, R., Just, R.E. 2010. Heterogeneity and distributional form of farm-level yields. American Journal of Agricultural Economics 93, 144-160.

Coles, S. 2001. An introduction to statistical modeling of extreme values. Springer London..

Embrechts, P., McNeil, A., Straumann, D. 2002. Correlation and dependence in risk management: properties and pitfalls In: Risk Management: Value at Risk and Beyond, ed. M.A.H. Dempster, Cambridge University Press, Cambridge, 176-223.

Goodwin, B.K., Hungerford, A. 2015. Copula-based models of systemic risk in U.S. agriculture: Implications for crop insurance and reinsurance contracts. American Journal of Agricultural Economics (in press). 
419 Hazell, P, Anderson, J., Balzer, N., Hastrup Clemmensen, A., Hess, U., Rispoli, F. 2010.

420 Potential for scale and sustainability in weather index insurance for agriculture and rural

421 livelihoods. International Fund for Agricultural Development and World Food Programme.

422 Lui, W.T. and F.N. Kogan. 1996. Monitoring regional drought using the vegetation condition 423 index. International Journal of Remote Sensing 17, 2761-2782.

424 Kellner, U., Musshoff, O. 2012. Precipitation or water capacity indices? An analysis of the 425 benefits of alternative underlyings for index insurance. Agricultural Systems 104, 645-653

426 Kogan, F., Guo, W., Strashnaia, A., Kleshenko, A., Chub, O., Virchenko, O. 2015. Modelling 427 and prediction of crop losses from NOAA polar-orbiting operational satellites. Geomatics, $428 \quad$ Natural Hazards and Risk (in press).

429 Kogan, F., Salazar, L., Roytman., L. 2012. Estimation of crop production using satellite-based $430 \quad$ vegetation health indices in Kansas. International Journal of Remote Sensing 33(9), 27984312814.

432 Kogan, F., Gitelson, A., Zakarin, E., Spivak, L., Lebed, L. 2003. AVHRR-based spectral 433 vegetation index for quantitative assessment of vegetation state and productivity: Calibration $434 \quad$ and validation. Photogrammetric engineering and remote sensing, 69(8), 899-906.

435 Kogan, F.N. 1998. A typical pattern of vegetation conditions in southern Africa during El-Nino 436 years detected from AVHRR data using three-channel numerical index. International $437 \quad$ Journal of Remote Sensing, 19(18), 3689-95.

438 Kogan, F. N. 1995. Drought of the late 1980s in the United States as derived from NOAA polar439 orbiting satellite data. Bulletin of the American Meteorological Society 76, 655-668. 
440 Mainik, G., Schaanning, E. 2012. On dependence consistency of CoVaR and some other 441 systemic risk measures. RiskLab, Department of Mathematics, ETH Zurich $442 \quad$ (http://arxiv.org/pdf/1207.3464v3.pdf).

443 Makaudze, E.M., Miranda, M.J. 2010. Catastrophic drought insurance based on remotely Sensed 444 normalized difference vegetation index for smallholder farmers in Zimbabwe. Agrekon $445 \quad 49(1), 418-432$.

446 McNeil A, Frey R, Embrechts P. 2005. Quantitative Risk Management, Princeton University 447 Press, Princeton.

448 Miranda, M.J., Farrin, K. 2012. A index insurance for developing countries. Applied Economic 449 Perspectives and Policy, 34 (3), 391-427.

450 National Agency of Statistics of the Republic of Kazakhstan. 451 http://www.stat.kz/digital/selskoe_hoz/Pages/default.aspx, accessed on January 11, 2012.

452 Nelsen, R. B. 1999. An Introduction to Copulas. Springer, New York.

453 Skees, J. R., Black, J. R., Barnett, B. J. 1997. Designing and rating an area yield crop insurance $454 \quad$ contract. American Journal of Agricultural Economics 79, 430-438.

455 Sklar A. 1959. Fonctions de répartition à n dimension et leurs marges, Publ. Inst. Stat. Univ. 456 Paris, 8, 299-231.

457 Spivak, L., Vitkovskaya, I., Batyrbaeva, M. 2008. Analysis of intra-seasonal variations in the 458 productivity of vegetation in Kazakhstan, using time series remote sensing. Bulletin of 459 National Academy of Sciences of the Republic of Kazakhstan: Series in Physics and $460 \quad$ Mathematics 4, 29-32. 
461 Suleimenov, M.K., Akshalov, K.A. 2011. Productivity and quality of spring wheat grain subject 462 to cultivation technology, crop rotation and weather. Bulletin of Agricultural Sciences of $463 \quad$ Kazakhstan 630, 17-21.

464 Turvey, C. G. 2001. Weather derivatives for specific event risks in agriculture. Review of 465 Agricultural Economics 23, 333-351.

466 Unganai, L.S., Kogan, F.N. 1998. Drought monitoring and corn yield estimation in Southern 467 Africa from AVHRR data. Remote sensing of environment, 63(3), 219-232

468 USDA Foreign Agricultural Service. Kazakhstan - 2011 Grain and Feed Annual Report. 469 http://gain.fas.usda.gov/, accessed on January 11, 2012.

470 USDA 1994. USDA Agricultural Handbook, Handbook No 664. Major World Crop Areas and $471 \quad$ Climate Profile, 157-170.

472 Vedenov, D.V. 2008. Application of copulas to estimation of joint crop yield distributions. 473 Contributed paper at the Annual Meeting of the AAEA 2008, Orlando, USA, July 27-29.

474 Vedenov, D. V., Barnett, B. J. 2004. Efficiency of weather derivatives as primary crop insurance 475 instruments. Journal of Agricultural and Resource Economics 29, 387-403. 


\section{TABLES}

Table 1. Aggregation of VH pixels within each county

\begin{tabular}{|l|l|c|l|c|c|}
\hline Oblast & Region & $\begin{array}{l}\text { Number on } \\
\text { the Fig 1 map }\end{array}$ & $\begin{array}{l}\text { Latitude } \\
\text { range, }{ }^{\circ} \mathrm{N}\end{array}$ & $\begin{array}{l}\text { Longitude } \\
\text { range, }{ }^{\circ} \mathrm{E}\end{array}$ & $\begin{array}{l}\text { Number } \\
\text { of pixels }\end{array}$ \\
\hline Akmola & Zelinograd & 1 & $50.4-51.2$ & $71.2-72.0$ & 30 \\
\hline & Atbasar & 2 & $50.7-51.7$ & $68.2-68.9$ & 24 \\
\hline Kostanay & Ezil & 3 & $51.4-51.8$ & $66.0-67.3$ & 25 \\
\hline & Kenis & 4 & $52.0-52.5$ & $61.3-62.4$ & 27 \\
\hline
\end{tabular}

Source: https://ru.wikipedia.org/wiki/

Table 2. Copula dependence parameter estimates at the county level

\begin{tabular}{lccccc}
\hline County & week & Gaussian & Clayton & Frank & surv. Gumbel \\
\hline$\underline{V C I}$ & & & & & \\
C1 Zelinograd & $28-31$ & 0.69 & 1.86 & 5.42 & 1.93 \\
C2 Atbasar & $29-32$ & 0.78 & 2.10 & 5.95 & 2.05 \\
C3 Esil & $29-32$ & 0.64 & 1.94 & 2.67 & 1.79 \\
C4 Denis & $28-31$ & 0.64 & 1.59 & 4.79 & 1.80 \\
C5 Kamysty & $26-29$ & 0.70 & 1.97 & 5.60 & 1.97 \\
$T C I$ & & & & & \\
C1 Zelinograd & $31-34$ & 0.72 & 1.41 & 4.34 & 1.70 \\
C2 Atbasar & $31-34$ & 0.75 & 0.89 & 4.07 & 1.45 \\
C3 Esil & $29-32$ & 0.64 & 1.76 & 2.80 & 1.79 \\
C4 Denis & $25-28$ & 0.71 & 1.90 & 5.52 & 1.95 \\
C5 Kamysty & $26-29$ & 0.79 & 1.94 & 5.26 & 1.97 \\
\hline
\end{tabular}

Note: the estimates for the Gaussian copula correspond with the respective values of the Pearson correlation coefficient. 
Table 3. Downside risk reduction estimates for VCI and TCI (two index selection alternatives)

\begin{tabular}{|c|c|c|c|c|}
\hline & $\mathrm{VCl}$ & & TC & \\
\hline & surv Gumbel & Frank & surv Gumbe & \\
\hline
\end{tabular}

County-yield based index selection

$\begin{array}{lllll}\text { C1 Zelinograd } & 0.28 & 0.25 & 0.34 & 0.32 \\ \text { C2 Atbasar } & 0.28 & 0.24 & 0.17 & 0.14 \\ \text { C3 Esil } & 0.12 & 0.10 & 0.15 & 0.12 \\ \text { C4 Denis } & 0.14 & 0.12 & 0.39 & 0.37 \\ \text { C5 Kamysty } & 0.44 & 0.40 & 0.38 & 0.34 \\ \text { Whole sample } & 0.25 & 0.22 & 0.29 & 0.26\end{array}$

Farm-yield based index selection

\begin{tabular}{lllll} 
C1 Zelinograd & 0.57 & 0.52 & 0.38 & 0.34 \\
C2 Atbasar & 0.26 & 0.22 & 0.17 & 0.15 \\
C3 Esil & 0.18 & 0.14 & 0.16 & 0.12 \\
C4 Denis & 0.37 & 0.35 & 0.42 & 0.39 \\
C5 Kamysty & 0.52 & 0.48 & 0.38 & 0.34 \\
Whole sample & 0.39 & 0.35 & 0.30 & 0.27 \\
\hline
\end{tabular}




\section{FIGURES}

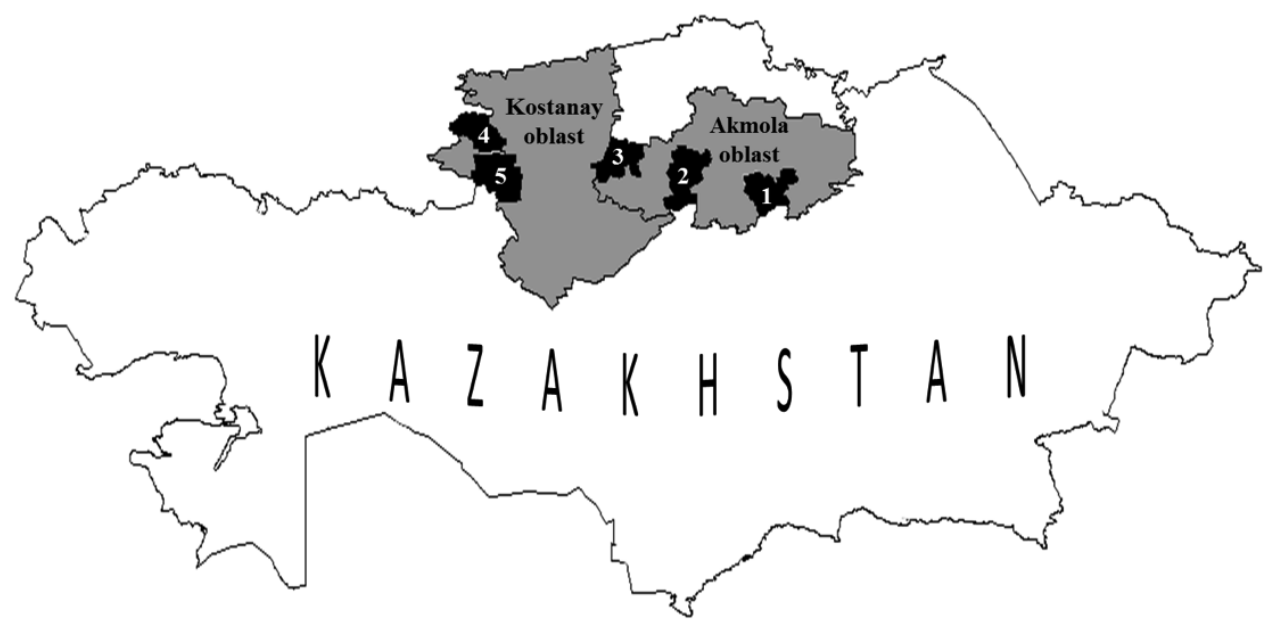

Note: 1 -Zelinograd county, 2 - Atbasar county, 3 - Esil county, 4 - Denis county, 5 - Kamysty county.

Figure 1. Location of the study counties

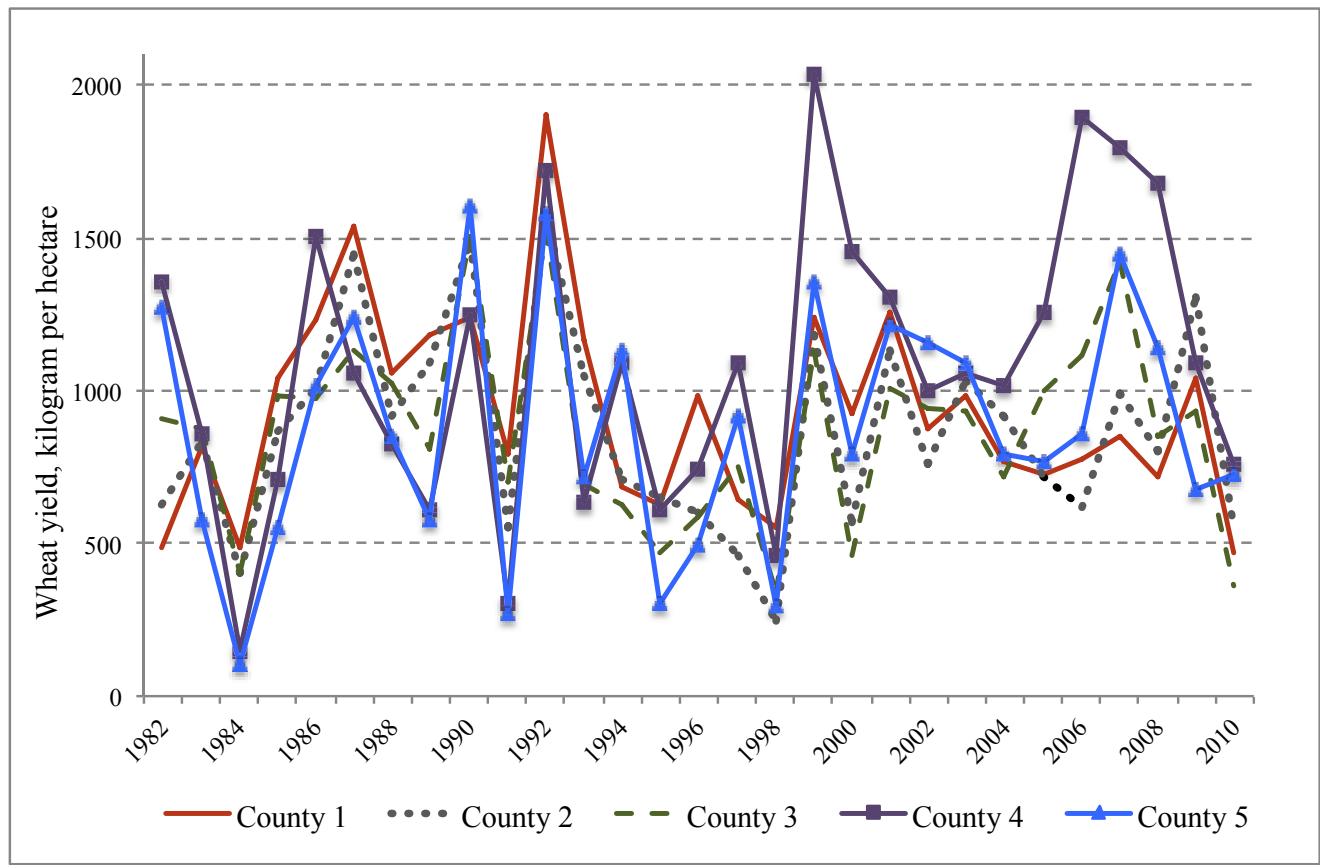

Source: Regional offices of statistics

Figure 2. Wheat yield time series for 5 study counties from 1982 to 2010 


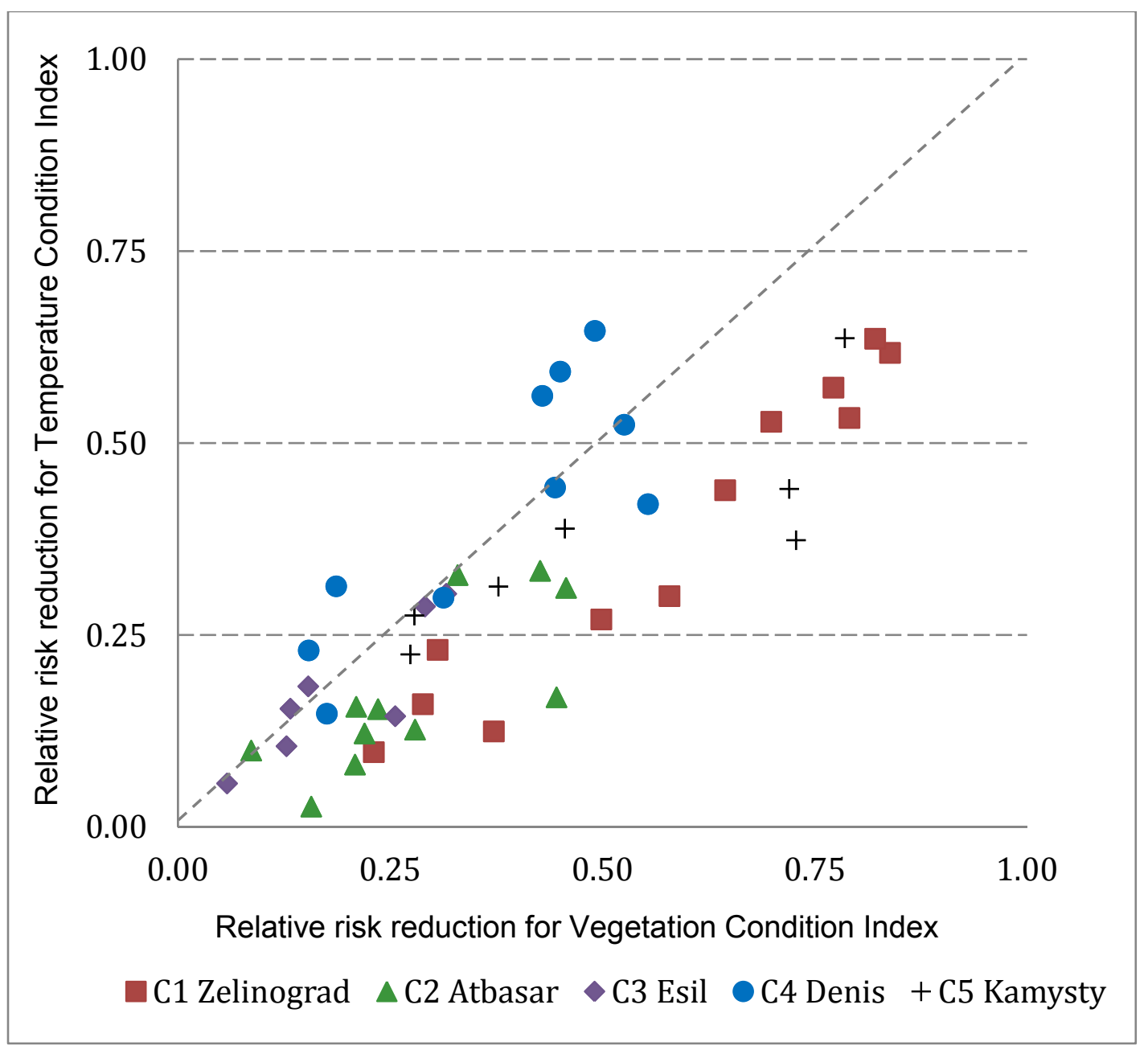

Note: each point corresponds with a sample farm and shows relative risk reduction due to insurance based on Vegetation Condition Index (x-axis) and Temperature Condition Index (y-axis).

Figure 3. Relative risk reduction estimates for two satellite-based vegetation health indices, Vegetation Condition Index and Temperature Condition Index, using survival Gumbel copula model 